ABSTRACT

Challenging the Centre: Asylum Seekers Encounter Native Citizens

In Paper Anchor (Paperiankkuri) at the Small Stage of the Finnish National

Theatre in 2011 a group of actors, dancers, asylum seekers and eventually also stage technicians (re-)enacted the asylum seekers' stories: how they had fled their

home countries, feared for their lives and faced problems in their country of destination, Finland. It brought the spotlight on asylum seekers, who occupy a marginal position in society and made them visible on many levels: they were present in the stories that were told on stage, in the encounter between performers and spectators and in an art institution that has great national significance.

The periphery and the centre, in this case the asylum seekers and the native Finns, met in shifting circumstances and also in a way that is characteristic of the theatre: the performers and spectators were simultaneously physically present, whereas the public debate on refugee issues usually takes place in written texts. In Paper Anchor, the asylum seekers also assumed the role of a witness, whereas in official processes they are obligated to defend themselves and search for evidence. The impact of Paper Anchor was largely based on the aesthetic form of the performance. Although the dominant power structures between the centre and the periphery remained untouched, theatre testified to its ability to affect the spectator through the presence of individual subjects and consequently their subject positions. The debate was shifted to differences within a culture instead of between cultures, as Rosi Braidotti writes: "It is the syntax of social relations, as well as their symbolic representation, that is in upheaval."

Keywords: asylum seekers, centre / periphery, national theatre, reception, community theatre.

BIOGRAPHY

Professor emerita Pirkko Koski was responsible for the Department of Theatre Research in the Institute of Art Research at the University of Helsinki and was the director of the Institute of Art Research until the end of 2007. Her research concentrates on performance analysis, historiography and Finnish theatre and its history. In addition to scholarly articles, she has published several books in these fields, the most recent of them Näyttelijänä Suomessa (Acting and Actors in

Finland) in 2013. She has also edited and co-edited several anthologies about Finnish theatre, translated Christopher B. Balme's The Cambridge Introduction to Theatre Studies into Finnish (in 2015) and edited volumes of scholarly articles translated into Finnish. pirkko.koski@helsinki.fi 


\section{Challenging the Centre Asylum Seekers Encounter Native Citizens}

\section{PIRKKO KOSKI}

Paper Anchor (Paperiankkuri) was performed at the Small Stage of the Finnish National Theatre in October 2011. In the production, a group of actors, dancers, asylum seekers and eventually also stage technicians re-enacted the stories of asylum seekers: how they had fled their home countries, feared for their lives and faced problems in their country of destination, Finland. Paper Anchor shone the spotlight on asylum seekers, who occupy a marginal position in society, and made them visible on many levels: they were present in the stories that were told on stage, in the encounter between performers and spectators and in an art institution that has great national significance. The reviews and newspaper articles also participated in the media debate on asylum.

In her book, Nomadic Subjects (2011), Rosi Bradotti discusses the crumbling of cultural homogeneity. This transformation has been evident in the political debates in Finland where the emphasis has shifted from the difference between cultures to the differences within each culture. Thus, in this case, the periphery confronts the centre, that is to say the asylum seekers meet the native Finns in shifting circumstances and on a level that is more complex than earlier, dualistic or polarized thinking. As Rosi Braidotti suggests, "[i]t is the syntax of social relations, as well as their symbolic representation, that is in upheaval". ${ }^{2}$ Related to art research, Agnes Woolley in her Contemporary Asylum Narratives (2014) writes about the communicability of the asylum experience and how the self-reflecting narrative fiction can shape an alternative "space of permanence that is hospitable to the heterogeneous experiences that constitute forced migration". ${ }^{3}$ She discusses "an ambivalent relationship to the aesthetic forms that seek to represent them, one which touches on questions of communicability, visibility and ethics". ${ }^{4}$ This leads us to look at Paper Anchor from another perspective.

The complexity was a central element in Paper Anchor, where the relationship between the centre and the periphery was unique in a way that is characteristic of the theatre by confronting the physical actuality of the asylum seekers: thus, whereas the public debate on refugee issues (in Finland) usually takes place in written texts, in this production the performers and spectators were simultaneously physically present. Moreover, whereas in official processes, asylum seekers are obligated to defend themselves and search for evidence, in Paper Anchor the asylum seekers also assumed the role of a witness. The power of theatre and performance was inherent in this dynamic. The thorough style of theatrical storytelling of Paper Anchor was therefore deeply affective. ${ }^{5}$

In this paper, I aim to show how this special style of theatrical storytelling was created and how it undermined the normative ideological position of the centre and promoted understanding. I will also discuss the significance of this production in a wider social context. First, I will describe the status and creation of the Paper Anchor performance as part of the Finnish National Theatre's Reception project. Then, I will discuss the performance itself and pay particular attention to the ways of "doing it 
differently", i.e. the means by which the theatre production challenged attitudes towards asylum seekers and broke through the safety net of the spectators' attitudes to affect them. Finally, I will reflect on the position of the production in the debate on asylum issues and refugees and place the discussion in the wider context of theatre and theatre research.

\section{THE NATIONAL THEATRE ADOPTS THE}

\section{ASYLUM ISSUE}

Paper Anchor was one of the initial so-called Fourth Venue projects that created touring productions within communities that are usually excluded from theatre venues. It was the first phase of a Reception Project at the Finnish National Theatre that was launched to facilitate the encounter between asylum seeking refugees and the majority population. The three-phased project began in spring 2011 and it continued for more than a year. Before the actual launch, the National Theatre carried out a community project, during which the project team familiarized themselves with the operations of a Helsinki-based reception centre for asylum seekers and ran drama workshops with the residents. Experiences from the workshops formed the basis of the Paper Anchor performance that I am investigating. The second phase, Paper Bridge (Paperisilta) was produced for a nationwide tour of more than 30 reception centres that accommodate asylum seekers. The cast of Paper Bridge included three professional artists - an actor, a dancer and a musician ${ }^{6}-$ and the production placed a lot of emphasis on music and dance-like movement. Each performance was followed by an informal discussion on the feelings and ideas evoked by the production. The third phase of the project, Paper Mouse (Paperihiiri) was a workshop-type performance for reception centre residents under ten years of age. It was based on a Native American tale about courage and stories told by child asylum seekers. Paper Mouse was created by three drama instructors. ${ }^{7}$ The intimacy of the performances of Paper Bridge and Paper Mouse and the post-show discussions strengthened the interactive nature of these particular events and the meaning of their activities can best be found on the micro level of personal encounters. By contrast, Paper Anchor, the target of my analysis, strove to realize the idea of an encounter with a wider group of people, i.e. theatre goers. Paper Anchor involved developing the stories that were created in the workshops and relying on the collaboration between artists and asylum seekers. The premiere was broadcast online by a national TV channel.

Paper Anchor was devised by Hanna Brotherus and Jussi Lehtonen, and directed and choreographed by Hanna Brotherus. The music and sound design, which was created by Sanna Salmenkallio and Mikko Perkoila, played an important part in the production; Perkoila also performed in the piece. The cast of performers included four former asylum seekers (Edina Bilajac, Naimo Mahamud, Tabanrouz Modaber and Matthew Rahmani), ${ }^{8}$ the actor Jussi Lehtonen, three dancers (Nina Hyvärinen, Alexandros Kotsopoulos and Liisa Pietikäinen) and two young boys (Jali Järvinen and Ruben Rissanen). Including the stage technicians, who joined some scenes in order to make them look like a larger crowd, there were a total of 16 performers on stage. The group of asylum seekers included men and women, who were rather young. They did not visibly represent the typical image of refugees in the Finnish debate on asylum seekers. Instead (and possibly partly because of that), they challenged that image and questioned the boundaries of exclusion and inclusion by appearing more 'ordinary' and 'familiar'; they looked more Finnish than was expected. ${ }^{10}$ The importance to the asylum seeker performers of having one's voice heard was confirmed by the discussions among the Paper Anchor performers, published by the National Theatre in Vastaanotto (Reception, 2012) and edited by Taija Helminen and Jussi Lehtonen. The asylum seekers talked there about what it had meant to them to perform in front of the National Theatre audience.

With regard to the style of the production, Jussi Lehtonen mentions that he was inspired by Augusto Boal's concept of "spect-actor", which suggests a subject that is a performer/actor and spectator at the same time. In Paper Anchor, the "spect-actors" contributed their proposals for elements of the performance in two phases: when they started the process in the reception centre and during the rehearsals. Material was selected from the workshops 
and interviews with the asylum seekers in the reception centre and complemented the experiences of the performers taking part in the Paper Anchor production. During the first rehearsal of Paper Anchor, the asylum seekers told their own stories and drew pictures on paper to illustrate their journey to Finland. After that, they enacted their route by walking through the rehearsal space. In this way, their movements grew into one of the fundamental elements of the performance. ${ }^{11}$ The production had a professional leader and director who made the artistic decisions and we might argue that the purpose of the working method was to construct a story that would be accepted as credible and that would thoroughly integrate the insights of the performers. The exchange between the different groups of performers became a mechanism for developing a means of communication between the performers and the audience who saw a ready-made performance.

\section{ASYLUM SEEKERS' STORIES AND TESTIMONIES ON STAGE}

Paper Anchor consisted of ten scenes, which were based on the asylum seekers' stories. ${ }^{12}$ The dramatic storytelling involved strong physical movement, which typically included a series of dance-like and fear-inspiring group scenes with the whole cast. The wide range of bodily expressions could be read physically as well as symbolically and socially. The set design consisted of elements that evoked visual and physical images. Jussi Lehtonen acted as the narrator of the play as well as serving as one of the actors in the group cast. In addition to group scenes with all the performers, the asylum seekers individually recounted stories from their past, in Finnish or in their native language, which were followed by a translation by the narrator.

At the beginning of the performance, the audience faced the metal fire curtain on stage. Lehtonen and the asylum seekers entered through a door in the curtain and Lehtonen proceeded to introduce the others, who repeated as a chorus Lehtonen's lines in their native language.(Fig. 1) The lines included instructions that are given to asylum seekers during their first informal session in Finland. This text had a strong subtext of suspicion. The whole scene, in which the asylum seekers stood on the narrow strip between the fire wall and the spectators, demonstrated the otherness of refugees. In an interview, Edina Bilajac, one of the asylum seekers, described the intimidating situation that was re-enacted on stage: people who have gone through extremely difficult experiences suddenly find themselves in confusing circumstances where they need to deal with a wide variety of things ranging from their official rights and duties to their house cleaning shifts. ${ }^{13}$ By performing this bureaucratic text, the actors managed to indicate an essential problem of being an asylum seeker: the high wall in front of you, being in full view of a Finnish audience and the lack of a common language and understanding, which focused attention on the dominant role of language.

The first scenes portrayed different phases in the asylum seekers' journey from their native countries to Finland, including the time they spent in reception centres. As the stage was revealed, a beam of light focused on a small boy, who was carrying a cardboard box, sitting in a small sled that was hard to move. At the same time, the narrator described the children's position in the asylum seekers' countries of origin and the increase in abuse as children grow older. Gradually, the beam of light shifted to a blindfolded group of dancers who were doing twitching movements on stage. The dancers took off their tops, which turned into bonds that tied their hands together. The dancers fell on the floor slowly, one by one, as if they were dead. At the end of the scene, the narrator read passages from an asylum seeker's medical certificate regarding injuries inflicted by torture. Two child actors followed the scene from the side of the stage. The dramaturgical focus was highlighted with expressive viola da gamba music. The performance continued with a description of a violence-filled journey. In stylized choreography, performers threw other performers against the iron wall at the side of the stage, climbed up the back wall, fell down, kicked each other, simulated rape and lay on the floor screaming and lamenting in agony. The sound of a drum was added to the music. The boys walked across the stage and stepped into the shoes that the adults had left behind. The flight of refugees ended with a soothing, humorous scene about the sleeping difficulties in a reception 


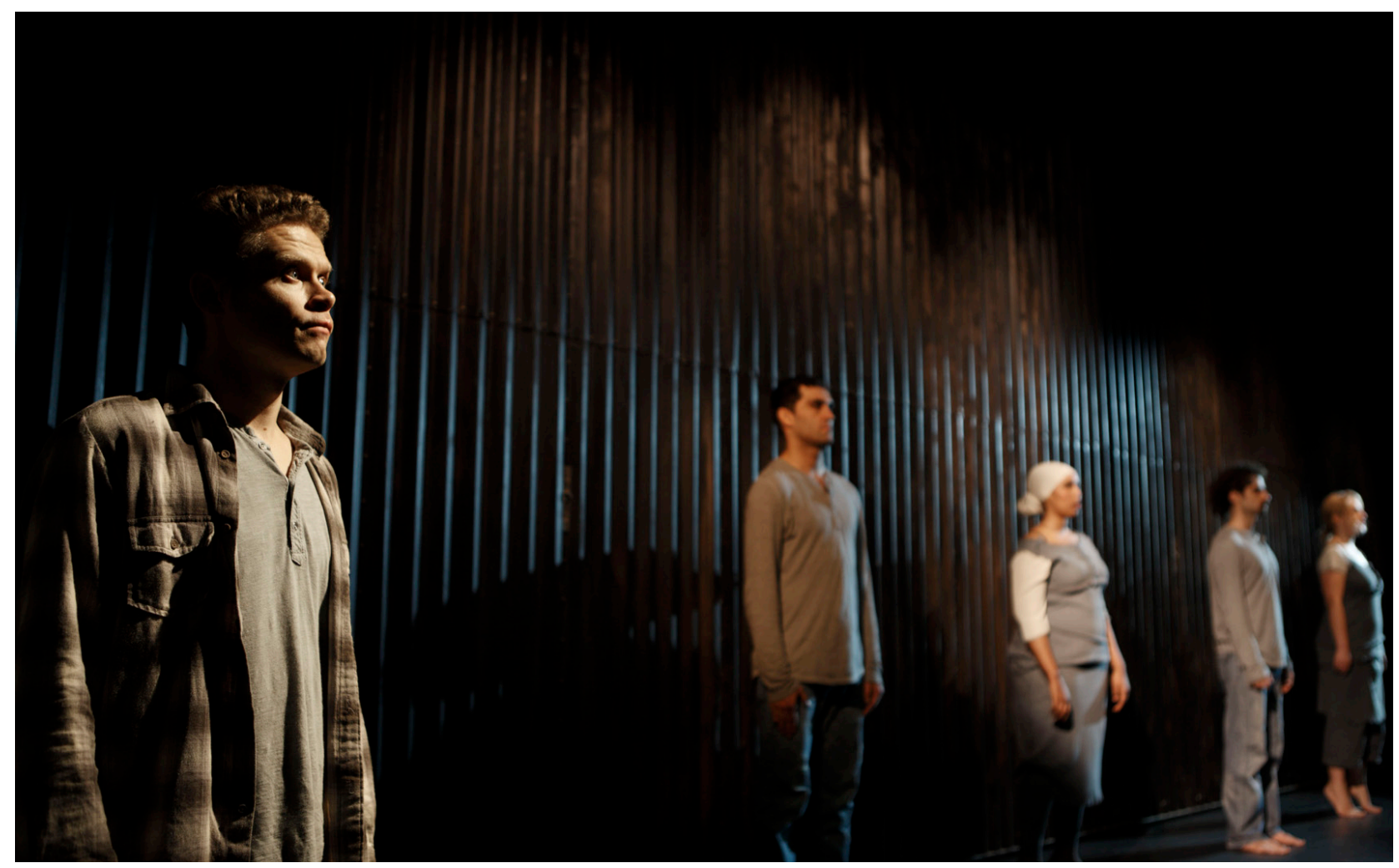

Fig. 1. Paper Anchor (2011), Finnish National Theatre, directed and choreographed by Hanna Brotherus, on stage, Jussi Lehtonen, Matthew Rahmani, Naimo Mahamud, Alexandros Kotsopoulos and Edina Bilajac. Photo: Nico Backström.

centre.

The following scenes were tied together by the use of paper that turned into various forms and acquired various meanings. First, in a scene that many spectators found deeply moving, performers picked up a sheet of paper hovering down from the ceiling - a negative decision on their residence permit application. (Fig. 2) They crumpled the papers, stuffed them into their mouths and shouted out their disappointment to the audience through the paper. At their side, the narrator read the text of the official statement. However, this was a theatricalized scene where the spectators could assume the role of a traditional theatre audience, which involves the suspension of disbelief; the construction of meaning did not require an affective response, unlike in other scenes. The scene acquired more depth and additional meaning in the subsequent interconnected scenes that depicted the horrors of the refugees' flight in a series of alternating moments of silence and fierce movement. Peaceful scenes where the actors carried each other tenderly, turned into a frantic run that was accompanied with music. The voice of the narrator and the asylum seeker's own testimony about the horrors of the flight were linked to stage action, where the performers wrapped themselves in paper, squeezed the paper into a pile and stood on it as if they were fleeing across the sea. The scenes ended with a film that had been made with a group of men in the reception centre the previous spring. In the film, the workshop participants drew pictures of a person on paper and continued the story with dance-like movements and gestures. The narrator related that more than half of the performers in the film had already been deported after their residence permit applications had been rejected.

A part of the dramatic structure of the performance was built on presenting the experiences of asylum seekers in their own voice and with their emphasized presence overlapping with group scenes. These sequences alternated the stage action from group scenes to individuals recalling their personal experiences and they worked in the same way as Brecht's alienation effect. The sequences fore- 


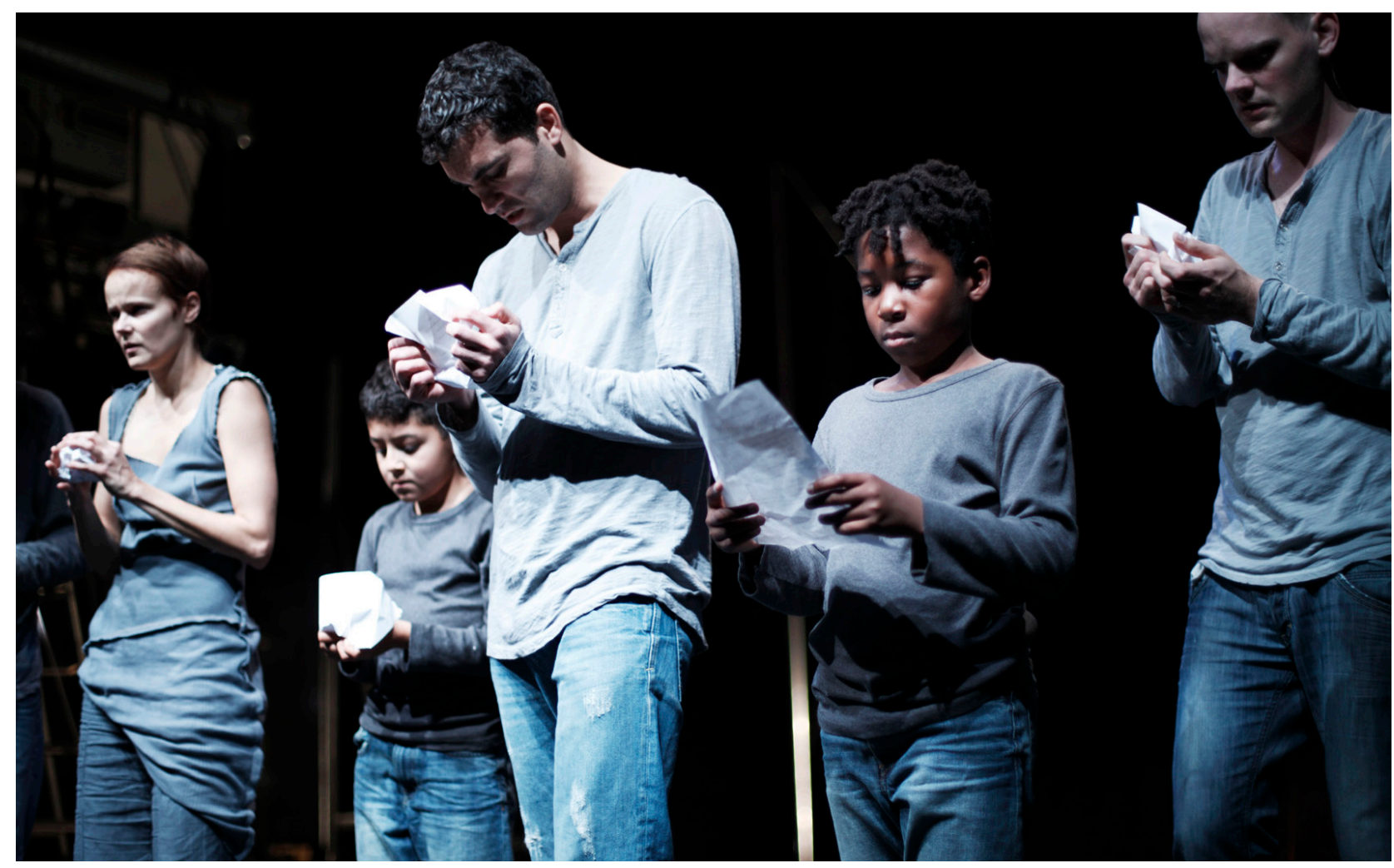

Fig. 2. Paper Anchor (2011), on stage Nina Hyvärinen, Jali Järvinen, Matthew Rahmani, Ruben Rissanen and Mikko Perkola. Photo: Nico Backström.

grounded themes that were important to each of the asylum seekers. These sequences also gave special agency to the performers, whose monologues were essential in creating the documentary credibility of the production. The asylum seekers performed their testimonies straight to the audience.

The image of motherhood and a safe home was evoked and challenged in several sequences. Naimo Mahamud carried a 'baby' wrapped in fabric and sang a Somali lullaby: "Your mother is not here, / no one knows if she is in heaven or on the earth. I She has taken her shoes with her. / We do not know if she will ever return." According to the singer, the song is known by all the people of Somalia. There are many lullabies about war because the war has been a central element in the lives of the Somali people for a long time. The image of motherhood unavoidably placed Naimo Mahamud's memories into a woman's position. It exploited the binary thinking of contrasting the safety of home with the frightening state of being "away" 14 , but broke that pattern by the strange combination of the intimacy of the mother and child with the physical violence that was also represented by the singing. For Naimo Mahamud herself, the performance gave a concrete form of life elsewhere, for example, in Somalia or elsewhere in Africa. ${ }^{15}$

Before the monologue by Bosnian Edina Bilajac, there was a scene that dealt with racism. The performers moved around threateningly, with their feet in buckets, which made their movements rough, and they shouted hate speeches with such lines as "Go home!". The action shifted from Finland to the refugee's country of origin and simultaneously the narrator started talking about the burial of corpses, mass graves and the stench of dead bodies. The little boys looked on, as the performers grappled each other and ran against each other in different ways. At the end of the scene, Edina Bilajac walked in front of the audience leaning on another woman and delivered her thoughts on the consequences and fear of racism - that the killing might start again. In a published discussion, she repeated her concern, but she also emphasized how important it was to express that fear. Nevertheless, the on stage story was the tip of the iceberg; people tend to keep their most 
difficult and personal moments inside. According to Edina Bilajac, there were also other people with very difficult memories, but "on stage I was alone and I alone represented my own story." 16 In this way, she personally and strongly distanced herself from the violence, which had been a predominant part of her Balkan community. She recounted that "[i]t is important to me that no one can come afterwards and say to me that I had ever accepted this matter, the state of the world and racism. I am against it." ${ }^{17}$ The beginning of this sequence connected the theme of racism also to Finland, which had been her destination.

The monologues of Iranian Matthew Rahmani had the strongest impact as testimony. He talked in his native language and the narrator translated it, but he also delivered some of his lines in Finnish. His story recounted the violence committed by the authorities in several countries in the course of his journey to Finland, how he had travelled, hiding in the boot of a truck, his wife's rape and attempted suicide, the initial negative decision on asylum as well as the fear of being deported back to Greece, which had been his country of entry into the Euro- pean Union. The monologue included a wish for a better future for his children; he wanted to offer his children the opportunity of receiving an education and a good life. He said: "I left my own country, culture and parents and came here." In a published discussion, he said that sitting alone on stage, speaking straight to the people in the audience and sharing his personal experience with the spectators was a powerful experience for him and gave him a lot of self-confidence. ${ }^{18}$

The final sequence represented the slow transition to a legitimate status in the target country. The image of the little boy's journey on a sled, seen in the beginning, was repeated in the movement of the whole group. All performers arrived very slowly from the back corner of the stage towards the audience. They were sitting on sleds, using their hands to move forward. ${ }^{19}$ (Fig. 3) In the middle of the stage, they changed direction. The movement created a rhythmical sound and was extremely slow.

Hanna Brotherus, the director of the performance, has explained how the movement was invented. The two child performers participated in a long rehearsal, where everybody was showing signs

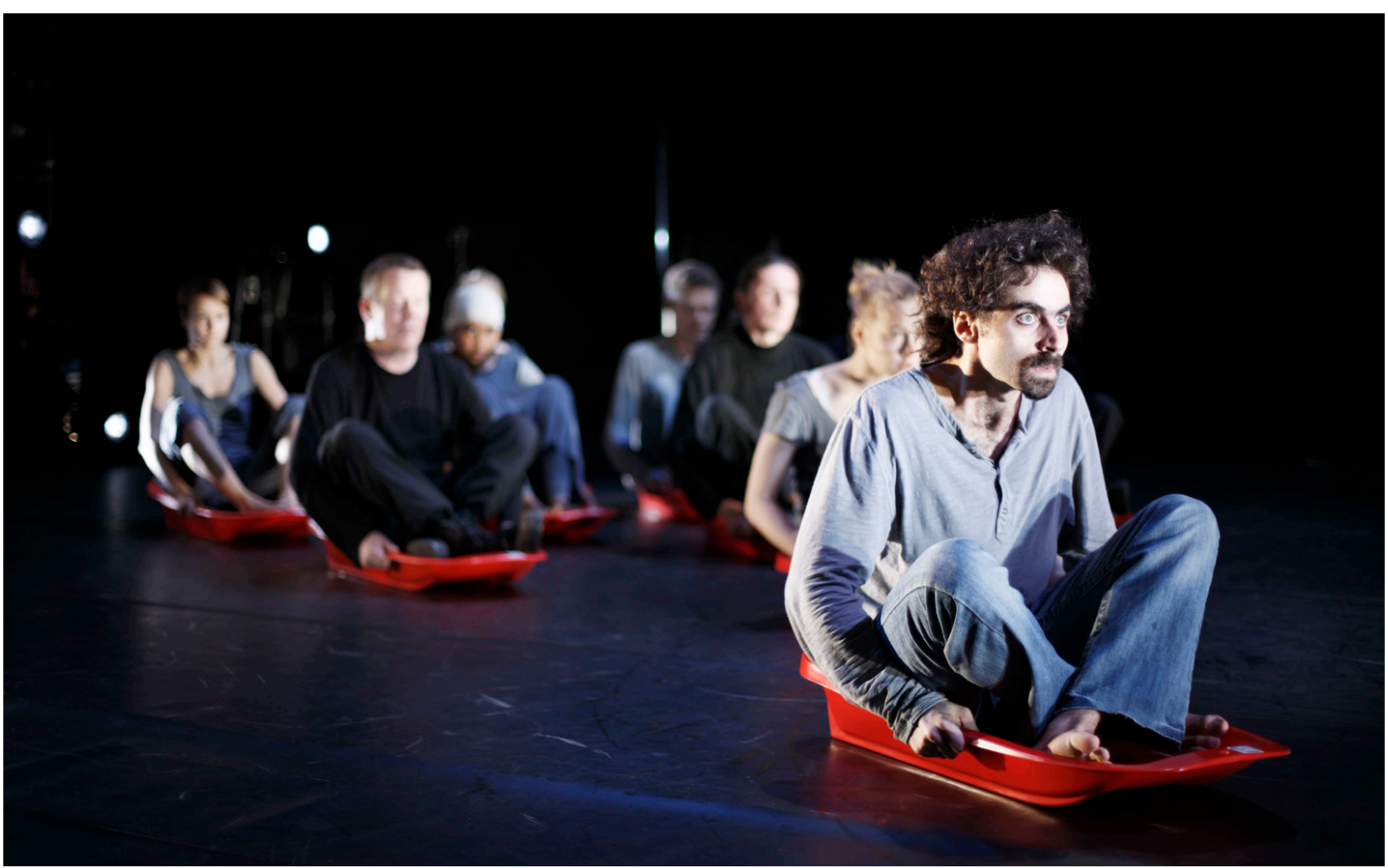

Fig. 3. Paper Anchor (2011), in the first row, Alexandros Kotsopoulos. Photo: Nico Backström. 
of exhaustion. She gave the others a break and remained on stage with the two boys. "I asked Jali to sit on that sled, 'Let's try something a bit silly'. I asked him to move with the sled and immediately I got the shivers, a feeling that I saw something truly impressive. I said to Jali, 'You're great', and he looked at me a bit amazed and said, 'Oh yeah, this sled does not slide at all'." ${ }^{20}$ The performers experienced the sequence as physical exertion. One of them, Mathew Rahmani has said that " $\mathrm{t}]$ he funniest moment was that end sequence with sleds. Laughter was sometimes close when adults tugged their sleds across the stage. And it was also difficult." 21 The spectators did not laugh. To me this was one of the most touching images of the piece and bound the messages of the performance together. The slow integration and fear of being sent back became visible and concrete. The sequence was powerful because this time the spectators were expected to construct the meaning, not the performers. This strong scenic image with no dialogue could not be interpreted without emotional imagination. It captured the theatrical power of visual and physical expression, affecting the spectator profoundly, surpassing language-based communication.

\section{THE MEANS TO AWAKEN UNDERSTANDING}

In her book Refugees, Theatre and Crisis (2012), Alison Jeffers examines refugees' stories and discusses theatre productions made by and about refugees. Jeffers justifies the role of refugee theatre in that it "allows us to address specifics where diaspora space is small enough to examine moments of encounter; the space between two individuals on a stage, for example, or the space in which an audience and performers meet". ${ }^{22}$ Paper Anchor is a good example of this.

The goal of Paper Anchor was to establish a new kind of connection between the performance and the audience and to increase understanding between asylum seekers and native Finns. The key element was to face people, issues and otherness. The selected means included physical and visual expression and music instead of delivering dialogue from behind the 'fourth wall'. The speech was directed at the audience, which recalls the use by Brecht of tex- tual placards, and it forced the spectator to consider the message transmitted by the visual images and movement. The power relations related to language, which are so important in real life, were neutralized. Moreover, the artists were conscious that Paper Anchor was an artistic, not a social project.

In Paper Anchor, Finnish theatre professionals were on stage with former asylum seekers, who were amateur actors but had an insight into the theme at hand. The Finnish performers joined in the storytelling by using their professional empathetic understanding, but they also had an acute awareness of the documentary dimension of the piece. The members of these two groups shared the same experiential space, but approached it from distinctly different perspectives and social positions. ${ }^{23}$ This had an impact on their position as the object of the spectators' attention and their subject position on stage. The insights and first-hand experience of the asylum seekers increased their position of power within the performance and challenged the hegemonic norms of society. They stepped "outside the expectations of silence and invisibility that are so often imposed upon them". ${ }^{24}$ Their visibility and presence were as important as their stories, especially because the production had no need to be evaluated with regard to the documented 'truth' that is usually demanded by government officials of asylum seekers. They were present 'as proof' in the context of the performance. We can say that the asylum seekers challenged several conventions: the reception frame of the audience, professionalism in the National Theatre and the border between the conventions of fact and fiction.

As some performers enacted their own stories, their double presence added special momentum to the performance. The strong documentary character of the production resembles what Bert O. States has written about the confusion that a real clock creates in a fictitious staging, as it indicates real and not fictitious time. ${ }^{25}$ The asylum seekers' testimonies, which evoked contradictory feelings and strengthened the speakers' stage presence, contributed to what Joseph Roach, in other types of performances, has referred to as "it": the "apparently effortless embodiment of contradictory qualities simultaneously", a combination of "strength and vulnerability, 
innocence and experience, and singularity and typicality". Roach has associated this kind of "it" with charisma and the intensity of being present in a performance. ${ }^{26}$ The asylum seekers with their physical presence on stage added a new level of reality to the theatrical performance. As Roach argues, "[v]isible or invisible, the wound leaves its emotional trace in every expression, especially the strongest". ${ }^{27}$ The asylum seekers' insights were undeniable.

Performing was a way of indicating the relationship with the painful past, but also of situating oneself among the performers and possibly the new society. Jane Goodall writes about the "democratization of Presence" and states that "performance provides the ways and means by which a 'Free-born people' can be formed". ${ }^{28}$ Matthew Rahmani's stage presence and his own experiences, which he related in the discussion, are special evidence of the possibility of this effect. Naimo Mahamud said that working in the project helped her to become part of Finnish society: she found out that in Finnish society women could do the same as men did. She understood what equality means, which was a great experience. What she appreciated most about Finland was the respect for other people. ${ }^{29}$

The reviews back up the significance of the affective experience. The emphasis on dance, movement and visual elements and featuring a narrator's voice and testimonies of people who have experienced the events, rather than on dialogue, had a major impact. Several reviewers pointed out the emotional impact of dance. According to them, it is more difficult to protect yourself from dance than words. The intense presence of the performers "dropped the statistics and surveys to the human level" 30 and "the embodiment of being a refugee through dance and movement" left a lot of room for thinking, ${ }^{31}$ which is not the case with xenophobia. The physicality of the performance distanced the communication from logocentricity by shifting the focus to other forms of representation. Furthermore, the only review that claimed that the emotional impact was somewhat limited was the one written about the television broadcast. $^{32}$

Alison Jeffers writes: 'Refugees' stories are troubling, troubled and troublesome. They are troubling because they are hard to hear, especially if the listen- er enjoys the privileges of the West; they are troubled, because persecution, trauma and suffering are essential elements of these stories, and they are troublesome, because lives depend on their claims for truth." 33 All the reviews had been glowing, and the reviewers admitted that they were impressed with the performance. However, some spectators, such as the Members of the Finnish Parliament who saw the production, were sorry that the performance was so bleak. Their remarks were indicative of the gulf between the testimony of those who had lived through the stories and some spectators, who may have wanted to see the stories as theatrical narratives only or at least as something which does not concern them personally. However, this could also be seen as a positive reaction: the message had come across.

\section{PERFORMING IN A PUBLIC SPACE AND PLACE}

Compared to other Nordic Countries, the number of asylum seekers in Finland at the time was very small: a total of 3088 . The largest number of asylum seekers came from (in descending order) Iraq, Somalia, Russia, Afghanistan, Iran, Syria and Nigeria. In 2011, out of the one hundred or so decisions on asylum for Nigerians, less than $20 \%$ were positive, whereas more than a third of Russian and almost half of the Afghani asylum seekers received a positive decision. For people from other countries, there were more positive decisions than negative ones, but the percentage was remarkably high only for Syrians. ${ }^{34}$ The number of asylum seekers is small because the number of asylum seekers that are not part of the quota programme is relatively low due to the distant geographical location of the country and the lack of significant refugee groups already living in Finland who could facilitate newcomers settling in Finland.

In Finnish society, asylum seekers occupy the most prominent position amongst refugees in newspapers and the media in general, as the topic of asylum is frequently addressed in the news and political debates. The disparity between the low number of asylum seekers and the extensive media publicity indicates that the Finnish public's image of asylum seekers and refugees in general is based on the im- 
ages provided by the media, rather than personal encounters with refugees or asylum seekers.

Another characteristic of the debate is that attention is not focused on the seekers' former experiences. By contrast, the question of refugees in general has been associated with other countries than Finland. We might even say that the Finnish compassion for refugees has been inversely proportional to the geographical distance from Finland to the country of origin. Paper Anchor introduced a new option in the Finnish media debate by providing testimony of the horrors experienced by individuals instead of by the media. It also participated indirectly in the debate through positive reviews and other newspaper stories. What had been distant and generalized was brought closer in the form of personal experience.

Alison Jeffers has written about the conditions in which refugees search for asylum. According to her, "all these endeavours take place against a background of fear, suspicion and mistrust on all sides". ${ }^{35}$ This mistrust has developed into a crisis "that goes to the very heart of questions about the nation state, identity and belonging". ${ }^{36}$ Elaine Aston has also surveyed British theatre productions about the liminality of the asylum-seeker, who faces the hostility and tightening attitudes. The truth value of the information presented by the refugees becomes important in order for the marginalized to convince those at the centre of society. ${ }^{37}$ Public attitudes in Finland also include suspicion and even occasional hostility. Although the asylum seekers in Paper Anchor praised the project, they also expressed frank opinions about their new social surroundings. For example, Tabanrouz Modaperin stated: "Although I've gotten used to this Finnish spirit of doing things after having been here for so long, I still feel that people could try to improve their social skills a little bit. There are folks who are much more social than me, but I still feel that there's this icy layer on the surface." ${ }^{8}$ The 'truth value' of Paper Anchor with its testimonies and documentary speeches inevitably worked against mistrust.

The former asylum seekers were performing at an institutional national venue. For them, performing at the Finnish National Theatre to a Finnish audience and sharing their own stories was a cathartic experience. They were in the midst of the process of integrating into a new society, and the context - the Finnish National Theatre - gave additional legitimation to their effort. The significance of the event grew as the premiere was broadcast online by a national television channel. According to the reviews, the performance proved that theatre can evoke compassion and served as evidence of "an institutional theatre's ability to find its place in the present" ${ }^{39}$ The event changed the position of all parties involved. In a wider system of social relations, the key element here is the symbolic capital provided by the institutions in the spirit of Pierre Bourdieu. What we are looking at is the interaction between the asylum seeker and the institution: the capital of both of them grew.

However, although the theatre considered Paper Anchor important, audiences were small and caused anxiety among the performers. There were 12 shows that attracted a total of 1817 spectators. The seating capacity of the auditorium is 311 , which means that on average, the auditorium was only half full. Hanna Brotherus has written: "It was difficult to accept the fact that Paper Anchor was not sold-out. We gave our all to the process, but after the initial hail and praise it was terribly disappointing that the debate ended abruptly." ${ }^{40}$ According to Liisa Malk$\mathrm{ki}$, a pattern which makes us look through a matrix of separate nations allows the refugee's own voice to disappear. According to her, the visual representations of refugees was used to show helpless characters. ${ }^{41}$ However, in Paper Anchor the asylum seekers performed as individuals with their own authentic voices and presence. But you had to come to the theatre in order to experience the performance and the asylum seekers' voices. Outside the theatre, the matrix of separate nations may have overshadowed the idea of dynamic and changing cultures ${ }^{42}$ and consequently an interest in engaging with asylum seekers and their assumed otherness on stage. This may partly explain why the auditorium was only half full: a thoroughly affective performance does not allow a cold reaction, and the safest way to reject the messages of the performance was to stay away from the theatre within the shelter of normative patterns.

Paper Anchor was hailed as a theatre production, 
but the reviews included few intertextual references to other theatre performances and most attention was focused on the treatment of the topic. However, this was not the first time the stories of refugees had been dealt with by means of theatre. Paper Anchor was not linked to previous joint productions of professionals and amateurs that dealt with the position of refugees in Finland, e.g. productions that had previously received a lot of public attention and were part of a multicultural project, such as Kassandra by Ritva Siikala. ${ }^{43}$ Also, there were no references to the contemporary political dramas and performances that deal with the position of socially excluded people. The performance was not connected to the growth of multiculturalism that is taking place in Finnish society, regardless of the low number of immigrants in Finland.

Paper Anchor was part of the Finnish National Theatre's repertoire, but the Theatre's new 'touring venue' and its work with excluded communities was still searching for its place and the link with theatre productions in general was not quite formed. These factors did not reduce the inner impact of the production, but the lack of intercultural links may have been one extra reason as to why the discussion and interest around the production died away quite quickly regardless of its positive reviews.

\section{CONCLUSIONS}

Paper Anchor brought the asylum seekers into the spotlight. In the wider Finnish social context, the discussion on refugee, asylum and immigration has been lively and irritatingly critical, especially compared with the small amount of refugees in the country. Paper Anchor gave a special tune to this public debate, albeit momentarily, because of its efficient quality of communication and the testimonial presence of asylum seekers on the national stage. The asylum issue was made corporeal and visible, and the production was also visible on TV, which complicated the general polarized thinking based principally on written texts. The centrality of the asylum seekers' former experiences outside Finland distanced the performance from local daily politics, but on the other hand, the affective power of these images brought the asylum seekers to the frontline as witnesses, which problematized critical attitudes. The impact may not have been broad, but it was deep and touched both performers and audience, and consequently both the centre and the margins in society. From the perspective of an individual asylum seeker, participating citizen or theatre maker, the experience was not much different from countries and cases where refugee issues have been considerably more common in society and art. All in all, Paper Anchor strengthened one's trust in the belief that theatre can, indeed, matter.

Trans. Sarka Hantula 


\section{NOTES AND REFERENCES}

1 Rosi Braidotti, Nomadic Subjects. Embodiment and Sexual Difference in Contemporary Feminist Theory, Columbia University Press, New York 2011, p. 8.

2 Ibid.

3 Agnes Woolley, Contemporary Asylum Narratives. Representing Refugees in the Twenty-First Century, Palgrave Macmillan, Houndmills, Basingstoke, p. 9.

4 Ibid., p. 3.

5 "Physical feelings that are connected to emotions are often referred to as affective states. Baruch Spinoza (1632-77) especially uses the term to refer to emotions in his book Ethics. An affect can also be understood more widely as any impulse that affects the mind." (www.tieteentermipankki.fi) In my case, affections are mainly linked with the kinesthetic empathy created by visual images and movement sensation.

6 Jussi Lehtonen, Niina Hyvärinen, Mikko Perkoila.

7 Mirjami Heikkinen, Elisa Salo, Katerina Zherbina.

8 The rehearsal period lasted five months. During the preceding community project, it had become clear that the application processes of asylum seekers might end abruptly and they might be deported at a few days' notice. The producers did not want to take the risk of performers receiving a negative decision and leaving the country during the rehearsal process. They had also considered engaging a group of asylum seekers, who had performed in a previous production at a reception centre, but some of them had already been deported. With the help of an immigrant association, the producers looked for people who had gone through the asylum-seeking process and received a residence permit. Cf. Taija Helminen, Jussi Lehtonen, Vastaanotto, Kirja kerrallaan, Suomen Kansallisteatteri, Helsinki 2012, p. 55. For the sake of clarity, this paper refers to the four refugees in the performance as asylum seekers, which describes their background and status in the performance.

9 The two boys were native Finns. The professional artists would not have had the necessary psychological training for handling situations in which refugee children might have recalled cruel situations similar to those which were performed on stage.

10 According to Alison Jeffers who has written about the plight of refugees, "[i]t is generally the most mobile that can and do travel". (Cf. Alison Jeffers, Refugees, Theatre and Crisis. Performing Global Identities, Palgrave Macmillan, Houndmills, Basingstoke 2012, p. 8. However, in the Finnish public debate, an asylum seeker is usually depicted through a narrower stereotypical difference, for example, physical appearance or race that differs from the majority of Finnish people. Most of the performers of Paper Anchor did not fit these generalizations, although they certainly represented "those who can and do travel".

11 Helminen, Lehtonen, op. cit., pp. 71, 149-50.

12 The scenes can be studied through numerous photos, the performance text, reviews and the international television recording of the first night by the national TV channel YLE Teema. The performers discussed their experiences in interviews which were published in a booklet Vastaanotto (op. cit.). The interviews are edited and the storytellers were necessarily dependent on the editors' attitudes, which may have influenced their choices but do not render them unreliable. The booklet also records the performance process.

13 Helminen, Lehtonen, op. cit., pp. 69-70.

14 Cf. Alison Jeffers, op. cit., pp. 4-5. Jeffers discusses the dangers of binary thinking connected to the terms 'refugee' and 'asylum seeker' and the concepts of "home" and "away": safe versus frightening. The production's image of motherhood inevitably rejects the possibility of simplification.

15 Helminen, Lehtonen, op. cit., p. 75.

16 Ibid., p. 67.

17 Ibid., p. 66.

18 Ibid., p. 70.

19 Ibid., p. 64. The idea for the movement in the final scene was not introduced until very close to the premiere and there were difficulties in finding numerous sleds before the winter sport period.

20 Ibid., p. 83.

21 Ibid., p. 74.

22 Jeffers, op. cit., p. 11.

23 Rosi Braidotti suggests that "[m]ainstream subject positions have to be challenged in relation to and interaction with the marginal subjects". Braidotti, op. cit., p. 5.

24 Cf. Jeffers, op. cit., p. 14. Jeffers investigates minority performances of activism, but I can see the same happening in Paper Anchor, albeit on a different scale.

25 Bert O. States, Great Reckognings in Little Rooms. On the Phenomenology of Theater, University of California Press, Berkeley, Los Angeles, London 1987, pp. 31-2.

26 Joseph R. Roach, It, University of Michigan Press, Ann Arbor 2007, p. 8. The cases that Roach refers to in these 
quotes are not identical to Paper Anchor, but they offer a perspective into the way the performance affected the audience.

27 Joseph R. Roach, "It" in Theatre Journal, vol. 56, no. 4, 2004, p. 566.

28 Jane Goodall, Stage Presence, Routledge, London and New York 2008, p. 12. She also refers to Roach.

29 Helminen, Lehtonen, op. cit., pp. 75, 77.

30 Annikki Alku, "Pieni pala turvaa hakevien todellisuudesta" (A Small Piece of Safety Seekers' Reality) in Uutispäivä Demari, 19 October 2011.

31 Soila Lehtonen, "Kuka oikein saa elää ja missä?” (Who Has the Right to Live and Where?) in Aamulehti, 14 October 2011.

32 J. T. Laakso, "Paperiankkuri on helppo ohittaa" (Paper Anchor is Easy to Dismiss) in Etelä-Suomen Sanomat, 16 October 2011 (about the TV production); Soila Lehtonen, "Kuka oikein saa elää ja missä?" (Who Has the Right to Live and Where?) in Aamulehti, 14 October 2011; Matti Saarela, "Typerä yleistys taittaa kärjen Paperiankkurin humanismilta" (Stupid Generalization Takes the Edge Off Humansim) in Etelä-Saimaa, 14 October 2011 (about the TV production); Isabella Rohgers, "Ondskan dansar i invandringspolitiken" (Evil Dances in Immigration Politics) in Hufvustadsbladet, 14 October 2011; Minna Tawast, "Ankkurit myrskyssä" in Tanssi no. 4-5, 2011, p. 47; Annukka Ruuskanen, "Uusi rautaesirippu on totta" (New Iron Curtain is a Reality) in Teatteri, no. 7, 2011, p. 5; Marja Kuparinen, "Liike tavoittaa rankan tunteen" (Movement Captures Difficult Emotion) in Kirkko ja kaupunki, no. 39, 2011, p. 10; Annikki Alku, "Pieni pala turvaa hakevien todellisuudesta" (A Small Piece of Safety Seekers' Reality) in Uutispäivä Demari, 19 October 2011; Maria Säkö, "Paperiankkuri hiipii ihon alle" (Paper Anchor Crawls Under your Skin) in Helsingin Sanomat, 14 October 2011.

33 Jeffers, op. cit., pp. 1-2.

34 Helminen, Lehtonen, op. cit., pp. 155-6.

35 Jeffers, op. cit., p. 13.

36 Ibid., p. 4.

37 Elaine Aston, "The 'Bogus Woman': Feminism and Asylum Theatre" in Modern Drama, vol. XLVI, no. 1, 2003, pp. 1-2, 12.

38 Helminen, Lehtonen, op. cit., p. 73

39 Isabella Rothgerg, "Onskan dansar i invandringspolitiken" (Evil Dances in Immigration Politics) in Hufvudstadsbladet, 14 October 2011.
40 Ibid., p. 82.

41 Cf. Laura Huttunen, "Historialliset kontekstit ja asioiden kansallinen järjestys" in Kulttuuri, paikka ja muuttoliike, Liisa Malkki, ed., Vastapaino, Jyväskylä 2012, pp. 9, 12-13.

42 Ibid., p. 10.

43 See e.g. Hanna Suutela, "Who Can Testify on Stage about Finnish Reality? Rainbow and the Kassandra 2000 Program Challenges National Hegemony" in Nordic Theatre Studies, vol. 15, 2002/3, pp. 106-18. The essay analyzes a multi-cultural performance entitled The Rainbow and its relationship to a multi-layered national identity. 